\title{
Characteristics of lipid substances activating the ileal brake in the rat
}

\author{
N J Brown, N W Read, A Richardson, R D E Rumsey, C Bogentoft
}

\begin{abstract}
Studies were carried out in 36 adult male rats to determine the characteristics of lipid substances which, after infusion into the ileum, slow the stomach to caecum transit time of the head of a bean meal in the rat. Stomach to caecum transit time was measured by environmental hydrogen analysis. Ileal infusion of a range of free fatty acids including petroselinic, oleic, myristoleic, erucic, linoleic, and linolenic all significantly slowed stomach to caecum transit time, as did the detergents (sodium bis (2-ethyl hexyl) sulphosuccinate and sodium linoleyl sulphate), the triglyceride corn oil, and the phospholipid lecithin. Although the lipid soluble deconjugated bile acid deoxycholic acid slowed stomach to caecum transit time, the water soluble conjugated bile acid taurocholic acid accelerated it. Infusion of the lipid alcohol oleyl alcohol and the calcium chelating agent disodium edetate (EDTA) into the ileum did not delay the passage of the meal through the stomach and small intestine. The diversity of lipid substances activating the ileal brake suggest a nonspecific effect by lipid soluble substances that can penetrate cell membranes. The lack of effect of EDTA suggested that calcium binding was not important.
\end{abstract}

Ileal infusion of triglyceride emulsions delay gastric emptying and small bowel transit in human volunteers ${ }^{12}$ and stomach to caecum transit in rats. ${ }^{3}$ The experiments described in this paper were designed to elucidate the possible mechanism by which fat soluble substances may interact with receptor mechanisms in the ileal epithelium, by determining the range of substances that activate the ileal brake mechanism. Measurement of stomach to caecum transit time using environmental hydrogen analysis during infusion of test substances via an ileal cannula allowed us to screen a large number of compounds. ${ }^{3}$ These included a range of free fatty

TABLE I Substances tested

\begin{tabular}{lllc}
\hline Test substances & Group of compound & Vehicle & $m M$ \\
\hline Oleic acid (Sigma) & Fatty acid C18:1 & Emulsifier & $0 \cdot 8$ \\
Linoleic acid (Sigma) & Fatty acid C18:2 & Emulsifier & $0 \cdot 8$ \\
Linolenic acid (Sigma) & Fatty acid C18:3 & Emulsifier & $0 \cdot 8$ \\
Erucic acid (Sigma) & Fatty acid C22 & Emulsifier & $0 \cdot 8$ \\
Myristoleic acid (Sigma) & Fatty acid C14 & Emulsifier & $0 \cdot 8$ \\
Petroselinic acid (Sigma) & Fatty acid C18:1 & Emulsifier & $0 \cdot 8$ \\
Oleyl alcohol (Sigma) & Alcohol & Emulsifier & $0 \cdot 8$ \\
Sodium bis (2-ethyl hexyl) sulphosuccinate (ACO) & Detergent & Water & $0 \cdot 1$ \\
Sodium linoleyl sulphate (ACO) & Detergent & Water & $0 \cdot 25$ \\
Lecithin (ACO) & Phospholipid & Saline & $0 \cdot 18$ \\
Corn oil (ACO) & Triglyceride & Emulsifier & $20 \%$ \\
Taurocholic acid (Sigma) & Bile acid & Saline & $0 \cdot 01$ \\
Deoxycholic acid (Sigma) & Bile acid & Saline & $0 \cdot 01$ \\
Disodium edetate (Sigma) & Calcium chelator & Saline & $0 \cdot 05$ \\
\hline
\end{tabular}

acids varying in chain length and the level of saturation, detergents, bile acids, phospholipids, and oleyl alcohol. We also investigated the effect of ileal infusion of the calcium chelating agent disodium edetate (EDTA), since Hunt ${ }^{4}$ had previously found that the delay in gastric emptying caused by lipid substances could be closely correlated with their affinity for calcium and mimicked by EDTA.

\section{Methods}

ANIMALS

Experiments were carried out on a total of 36 adult male albino rats, obtained from Sheffield Field Laboratories, weighing between 250 and $300 \mathrm{~g}$. The rats were equipped with chronic indwelling ileal cannulas and housed singly in cages. The animals were deprived of food (Diet 86, Oxoid, London, UK) 18 hours before the experiment but water was freely available. Animals were allowed at least one week postoperative recovery before any experiments were carried out.

PREPARATION OF TEST SUBSTANCES

The substances that were tested are listed in Table I. They included the triglyceride corn oil $(20 \%)$, a range of free fatty acids $(0 \cdot 8 \mathrm{M})$ varying in chain length, saturation, and the position of the double bond, the lipid alcohol oleyl alcohol $(0.8 \mathrm{M})$, the phospholipid lecithin $(0.18 \mathrm{M})$, the bile salts deocycholate $(0.01 \mathrm{M})$ and taurocholate $(0.01 \mathrm{M})$, two detergent substances sodium bis (2-ethyl hexyl) sulphosuccinate (AOT, 0.1 M) and sodium linoleyl sulphate (SLES, 0.25 M), and the calcium chaletor disodium edetate (EDTA, 0.05 M). Each of the substances was tested in at least six rats. All lipids were emulsified on ice by ultrasound (Soniprep 150, MSE Ltd, Crawley, Sussex, UK) using a physiological emulsifier containing $9.1 \mathrm{mM}$ glycerol (Sigma Chemical Co, St Louis, MO, USA), 16.8 mM Lalpha-phosphatidyl choline (Sigma Chemical), and $9.4 \mathrm{mM}$ taurocholic acid (Sigma Chemical) in sterile saline $0.9 \%$ (Travenol Laboratories Ltd, Thetford, Norfolk, UK). The resulting solution was isotonic and the $\mathrm{pH}$ was adjusted to $7 \cdot 0$. The two detergents were made up in water; the lecithin, bile acids, and EDTA in saline. Control solutions of saline, water, and the emulsifying solution were also tested before and after each series of experiments.

PREPARATION OF THE TEST MEAL

'Californian' white beans (H J Heinz Co Ltd, Hayes, Middlesex, UK) were washed to remove 


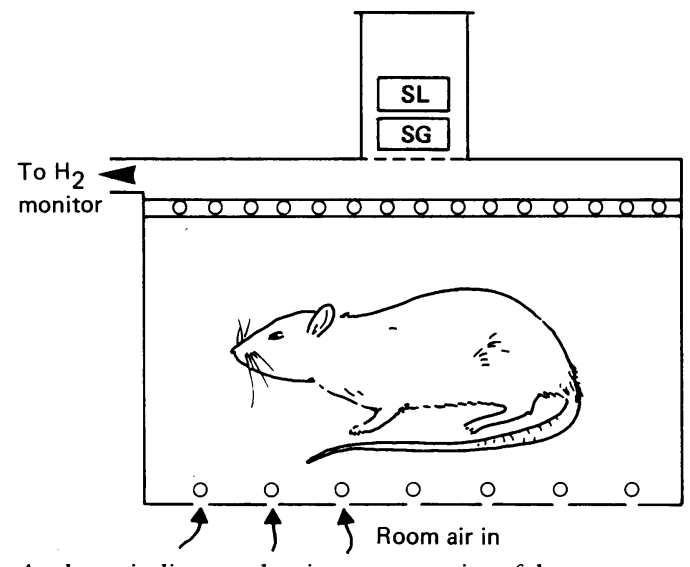

A schematic diagram showing a cross section of the perspex chamber from which exhaled breath hydrogen concentrations are monitored. $S L=$ soda lime, $S G=$ silica gel.

the tomato sauce, homogenised with a little water, and lactose (May \& Baker Ltd, Dagenham, UK) added to produce a concentration of $10 \% \mathrm{w} / \mathrm{v}$.

\section{SURGICAL PROCEDURE}

A plastic cannula (Silastic ID 0.02 in, OD 0.037 in, Dow Corning Corp, Medical Products, Midland, Michigan, USA), $25 \mathrm{~cm}$ in length, was implanted in the ileum of animals under barbiturate anaesthesia (Sagatal $60 \mathrm{mg} / \mathrm{kg}$; May \& Baker Ltd, Dagenham, UK). The abdomen was opened via a midline incision and the cannula placed in the ileal lumen approximately $20 \mathrm{~cm}$ proximal to the ileocaecal junction. The intestinal wound was closed by tying a pursestring suture around the cannula making sure the lumen of the cannula was not occluded. Sufficient cannula was left free in the abdominal cavity to allow the gastrointestinal tract full mobility. The abdominal incision was closed in two separate layers, the muscle and then the skin, using a sterile braided silk suture 5-0 (Mersilk, Ethicon, Edinburgh, Scotland). A small square of nylon mesh was attached to the cannula, 2-3 $\mathrm{cm}$ from its proximal end using silicon glue (Medical adhesive type A, Dow

TABLE II Stomach to caecum transit time (SCTT) of various substances

\begin{tabular}{|c|c|c|c|}
\hline \multirow[b]{2}{*}{ Substance } & \multicolumn{2}{|l|}{$S C T T(\min )$} & \multirow[b]{2}{*}{$\begin{array}{l}\text { Significance } \\
\text { level }\end{array}$} \\
\hline & $\begin{array}{l}\text { Control } \\
(\text { mean }(S E))\end{array}$ & $\begin{array}{l}\text { Test } \\
(\text { mean }(S E))\end{array}$ & \\
\hline \multicolumn{4}{|l|}{ Fatty acids $(n)$ : } \\
\hline Oleic $(7)$ & $98(8 \cdot 3)$ & $154 \cdot 3(9 \cdot 2)$ & $\mathrm{p}<0.001$ \\
\hline Linoleic (11) & $95 \cdot 5(4 \cdot 3)$ & $164 \cdot 5(13 \cdot 5)$ & $\mathrm{p}<0.01$ \\
\hline Linolenic (11) & $95 \cdot 5(4 \cdot 3)$ & $177 \cdot 3(13 \cdot 9)$ & $\mathrm{p}<0.01$ \\
\hline Erucic $(8)$ & $91 \cdot 8(7 \cdot 1)$ & $160(14 \cdot 4)$ & $\mathrm{p}<0.01$ \\
\hline Myristoleic (6) & $82.5(3.4)$ & $193 \cdot 3(11 \cdot 2)$ & $\mathrm{p}<0.01$ \\
\hline Petroselenic (6) & $90 \cdot 5(4 \cdot 8)$ & $158 \cdot 3(9 \cdot 8)$ & $\mathrm{p}<0.001$ \\
\hline \multicolumn{4}{|l|}{ Triglyceride: } \\
\hline $\begin{array}{l}\text { Phospholiprd: } \\
\text { Lecithin (13) }\end{array}$ & $96 \cdot 2(6 \cdot 4)$ & $157 \cdot 6(12 \cdot 9)$ & $\mathrm{p}<0.001$ \\
\hline Lipid alcohol: & $104.2(3.6)$ & $108.4(2.7)$ & NS \\
\hline \multicolumn{4}{|l|}{ Detrgents: } \\
\hline Sodium bis (2-ethyl hexyl) sulphosuccinate (7) & $116 \cdot 5(4 \cdot 6)$ & $174 \cdot 7(10 \cdot 2)$ & $\mathrm{p}<0.02$ \\
\hline \multicolumn{3}{|l|}{ Bile acids: } & $\mathrm{p}<0.01$ \\
\hline Taurocholic (6) & $98 \cdot 3(4 \cdot 8)$ & $77 \cdot 5(1 \cdot 1)$ & $\mathrm{p}<0.01$ \\
\hline Deoxycholic (6) & $98 \cdot 3(4 \cdot 8)$ & $148 \cdot 3(10 \cdot 8)$ & $\mathrm{p}<0.01$ \\
\hline \multicolumn{4}{|l|}{ Calcium chelator: } \\
\hline EDTA $(6)$ & $114(9 \cdot 8)$ & $110(5 \cdot 5)$ & NS \\
\hline
\end{tabular}

Significance levels relate to the difference between control and test stomach to caecum transit time values. $\mathrm{NS}=$ no significant difference.
Corning Corp, Medical Products). The cannula was tunnelled subcutaneously from an abdominal stab wound to the midscapular region where it was exteriorised via a cutaneous puncture wound, the piece of nylon mesh lying under the skin forming an anchorage point. The cannula was secured in position as the damaged tissues under the skin regenerated, forming a platform over the mesh. In the meantime three stitches were used to secure the cannula and the exposed end was covered with a blunt ended pin. Each rat was allowed a postoperative recovery period of one week before any experimental procedures were performed. Every day a small volume $(0 \cdot 3$ $\mathrm{ml}$ ) of saline was infused in the ileum of each rat to ensure the cannula remained patent.

\section{EXPERIMENTAL PROTOCOL}

Experiments were performed on batches of six animals simultaneously. Each animal was used to investigate the effect of a control and several test infusions on the passage of a meal through the stomach and small intestine. At least two days were allowed between testing the different substances. Control studies were carried out at the beginning and end of a series of experiments using the test substances.

After starvation for 18 hours, rats were placed in Bollman restraining cages and connected to the infusion pump (Braun, Germany) by a metal connector and plastic tubing. Solutions were infused into the ileum at a rate of $0.3 \mathrm{ml} / \mathrm{h}$ for 20 minutes. Then the rats were gavaged with $5 \mathrm{ml}$ of the bean/lactose test meal and placed in the perspex chambers (Figure). The perspex chambers provided a controlled environment from which hydrogen concentrations could be monitored easily and solutions infused into the animals without causing them any disturbance. The flow of room air through the chambers was kept constant at a rate of $100 \mathrm{ml} / \mathrm{min}$ by means of a pump, solenoid valve, and flowmeter. The gases in the chambers were continuously mixed by a small fan at the top of the perspex tower above the main body of the chamber. Soda lime and silica gel (BDH Chemicals Ltd, Poole, UK) were present in the perspex tower to absorb carbon dioxide and water vapour respectively. Gases were evacuated through perspex rods running the length of each chamber via a switching device. The contents of each chamber was sampled in turn every 10 minutes throughout the experiment and analysed for hydrogen concentration by means of a polarographic hydrogen monitor (GMI Medical Ltd, Renfrew, Scotland) which had been calibrated with a standard gas mixture. The infusion tube was attached to a pulley system allowing the animal free movement in the chamber. The infusion continued for a further 165 minutes after gavage.

Stomach to caecum transit time of the head of the bean/lactose test meal was defined as the time from gavage to an increase in the hydrogen concentration in the rats' environment of 2 parts per million sustained for at least three consecutive readings. ${ }^{3}$ This occurred when the unabsorbable carbohydrate component of the meal reached the colon and was fermented by the colonic bacteria. ${ }^{56}$ 
HISTOLOGY

Rats which had undergone infusion of oleic acid $(0.8 \mathrm{M})$, taurocholic acid $(0.01 \mathrm{M})$, or AOT $(0 \cdot 1$ $M)$ were killed and the section of the ileum to be investigated was dissected from the rat. This was gently washed with physiological saline and the lumen of each segment was filled with $10 \%$ formal saline making certain that the tissue was not distended. After fixation the tissue was processed and $5 \mu \mathrm{m}$ paraffin wax sections were cut and stained with haematoxylin and eosin.

\section{STATISTICAL ANALYSIS}

The differences in transit times during infusion of the different solutions was assessed using an analysis of variance test (Anova) and the MannWhitney $U$ test for non-parametric independent data.

\section{Results}

EFFECT OF FREE FATTY ACID, OLEYL ALCOHOL, AND PHOSPHOLIPIDS

Ileal infusion of corn oil emulsion, all the free fatty acids, and the phospholipid lecithin significantly slowed the passage of the head of the meal to the caecum (Table II). In contrast, oleyl alcohol had no significant effect on stomach to caecum transit time (Table II). There was no relationship between fatty acid chain length and the ability to delay transit time. When fatty acids of the same chain length were compared, neither the degree of saturation nor the position of the double bond appeared to influence the effect of the fatty acids on stomach to caecum transit.

EFFECT OF DETERGENTS, BILE ACIDS, AND EDTA Ileal infusion of each of the detergents (Table II) and the deconjugated bile acid deoxycholic acid (Table II) significantly slowed the passage of the head of the meal through the stomach and small intestine when compared with the appropriate control infusions. In contrast, infusion of the same concentration of taurocholic acid significantly accelerated stomach to caecum transit time (Table II).

Ileal infusion of the calcium chelating agent EDTA did not alter stomach to caecum transit time from the control values (Table II).

\section{EFFECT OF CONTROL ILEAL INFUSIONS}

The same six animals were used to investigate the effect of the three control infusions. There are no significant differences between the stomach to caecum transit times of the meal during any of the control infusions: (mean (SE) water 86.7 $(8 \cdot 0) \min (n=6)$, saline $100 \cdot 0(5 \cdot 2) \min (n=6)$, emulsifier $98.3(7 \cdot 0)$ min $(n=6))$ performed at the start of the studies or between these initial readings and those obtained from the same animals at the end of the series of experiments: (water $90.1(6.2) \mathrm{min}$, saline $95.5(9.7) \mathrm{min}$, emulsifier $90 \cdot 1(4 \cdot 2) \mathrm{min})$. abnormalities of the mucosal morphology during infusion of oleic acid or taurocholic acid, but the detergent infusion of AOT had caused villous disruption.

\section{Discussion}

Our results show that ileal infusion of a triglyceride, free fatty acids of different chain length and saturation, a phospholipid, detergents, and a deconjugated bile acid all delayed stomach to caecum transit time. The diversity of the substances capable of eliciting this response suggests the possibility of a common non-specific mechanism, but do not rule out mediation by different specific mechanisms. Histological examination of the intestine did not indicate that the effects were related to epithelial damage apart from after detergent infusion. The fact that all of the 'active' substances are lipid soluble suggests that the ability to partition into cell membranes may be a prerequisite for interacting with receptor mechanisms. This suggestion is supported by the observation that the more water soluble substance taurocholic acid that interacts with a membrane bound receptor did not delay stomach to caecum transit time, but actually caused a small but significant acceleration in stomach to caecum transit time. In a recent study Penagini and his colleagues ${ }^{7}$ showed that infusions of combinations of conjugated bile acids, glycocholic and glycochenodeoxycholic acid with lecithin, into the human jejunum delayed small bowel transit time and inhibited both jejunal and ileal motility.

The ability of a substance to partition into a cell membrane is probably not the sole prerequisite for stimulation of the ileal brake mechanism. Oleyl alcohol is a lipid soluble substance, yet it did not slow stomach to caecum transit time. Fatty acids differing in chain length and saturation do not differ appreciably in their oil/ water partition coefficients and they delayed stomach to caecum transit time with equal potency. The results suggest that the ability of a lipid soluble substance to trigger a delay in stomach to caecum transit must involve another stage that may have more specific structural requirements.

Many of the substances that are found to delay stomach to caecum transit time when infused into the ileum also delayed gastric emptying when incorporated into a liquid meal in human volunteers. ${ }^{4}$ Hunt explained the action of lipidsoluble substances on gastric emptying by their action in binding ionised calcium; since calcium is thought to be responsible for maintaining the integrity of the intercellular tight junctions, any agent which binds calcium would increase the permeability of the junctions causing the lateral intercellular spaces to shrink in response to the hyperosmotic duodenal contents after a meal ${ }^{8}$ and this, according to Hunt, ${ }^{4}$ would stimulate afferent nerves or release transmitters that delay gastric emptying. His argument was supported by the observation that the chelating agent EDTA also delayed gastric emptying. We were unable to influence stomach to caecum transit time by infusing the same concentration of EDTA as Hunt used in his experiments into 
the ileum. In any case, an osmotic effect seems an unlikely mechanism to explain the ileal brake mechanism since the pore size and epithelial permeability is so much less than in the duodenum, ${ }^{910}$ and hyperosmotic solutions infused into the ileum did not affect small bowel transit time or gastric emptying in humans ${ }^{11}$ or stomach to caecum transit time when infused into an ileal Thiry-Vella loop in the rat (unpublished observations).

The experimental design does not rule out the possiblity that the test substances may be acting by stimulating colonic receptors. We think this is an unlikely mechanism, however, because colonic infusion of lipids in humans did not slow small bowel transit time ${ }^{2}$ and infusion of lipids into isolated ileal loops in rats delayed small bowel transit time to the same extent as infusion into the intact ileum. ${ }^{12}$

Our results suggest that the interaction of lipid soluble substances with the ileal mechanism, which is responsible for delaying stomach to caecum transit, is non-specific and may depend on the ability of those substances to partition in the cell membrane. Our data do not indicate what effect this would have, but alterations of membrane permeability, release of transmitter substances, and stimulation of afferent neurones are possibilities and require further investigation.
The financial support of Kabi Invent AB, Huddinge, Sweden, is gratefully acknowledged.

1 Spiller RC, Trotman IF, Higgins BE, et al. The ileal brake inhibition of jejunal motility after ileal fat perfusion in man. Gut 1984; 25: 365-74.

2 Read NW, McFarlane A, Kinsman RI, et al. The effect of infusion of nutrient solutions into the ileum on gastrointestinal transit and plasma levels of neurotensin and intestinal transit and plasma levels of neurotensin

3 Brown NJ, Rumsey RDE, Read NW. Adaptation of hydrogen analysis to measure stomach to caecum transit time in the rat. Gut 1987; 28: 849-54.

4 Hunt JN. Does calcium mediate slowing of gastric emptying by fat in humans? Am $\mathcal{F}$ Physiol 1983; 244: G89-94.

5 Bond JH, Levitt MD. Investigation of small bowel transit time in man utilizing pulmonary hydrogen $\left(\mathrm{H}_{2}\right)$ measurements. f Clin Invest 1975; 85: 546-55.

6 Read NW, Miles CA, Fisher D, et al. Transit of a meal through the stomach, small intestine and colon in normal subjects and its role in the pathogenesis of diarrhea. Gastroenterology 1980; 79: 1276-82.

7 Penagini R, Misiewicz JJ, Frost PG. Effect of jejunal infusion of bile acids on small bowel transit and fasting jejunal motility in man. Gut 1988; 29: 789-94

8 Barker GR, Cochrane GMcL, Corbett GA, Dufton JF, Hunt JN, Roberts SK. Glucose, glycine and diglycine in test meals as stimuli to a duodenal osmoreceptor slowing gastric emptying. F Physiol 1978; 283: 341-6.

9 Fordtran JS, Rector FC, Ewton MF, Soter N, Kinney J. Permeability characteristics of the human small intestine. F Clin Invest 1965; 44: 1935-44.

10 Cotterell D, Kohn PG. Variation in tissue resistance in rat small intestine. Its relationship to observed potential small intestine. Its relationship to observed
changes. Biochim Biophys Acta 1970; 203: 179-81.

11 Welch IMcL, Cunningham KM, Read NW. Regulation of gastric emptying by ileal nutrients in man. Gastroenterology gastric emptying

12 Richardson A, Brown NJ, Rumsey RDE, Read NW. Effect of ileal infusion of various lipids and detergents on stomach to caecum transit time in the rat. Gut 1987; 28: A1355. 